\section{Slow Abstracts}

How useful are abstracts? Because of the expansion of scientific literature, many of the functions once performed by scientific journals are now taken over by the abstract journals. By scanning more primary publications than any individual is able to, the abstracts provide a running record of what has been published and keep their readers up to date.

But examination of two abstract journals in physics -Physics Abstracts, published by the Institution of Electrical Engineers, and Nuclear Science Abstracts, published by the United States Atomic Energy Commission-shows that their readers are by no means as up to date as they might be. The distribution curves show the time lags calculated for October editions of both abstract journals. The delay times are those between the publication of the original paper and the appearance of an abstract of it. The curves were calculated from the dates of original publication given in the abstracts. The figures thus take no account of the abstracts for which no date is given. The figures are based on two counts, each of 100 abstracts, taken at random from corresponding editions of Physics Abstracts and Nuclear Science Abstracts. The curves
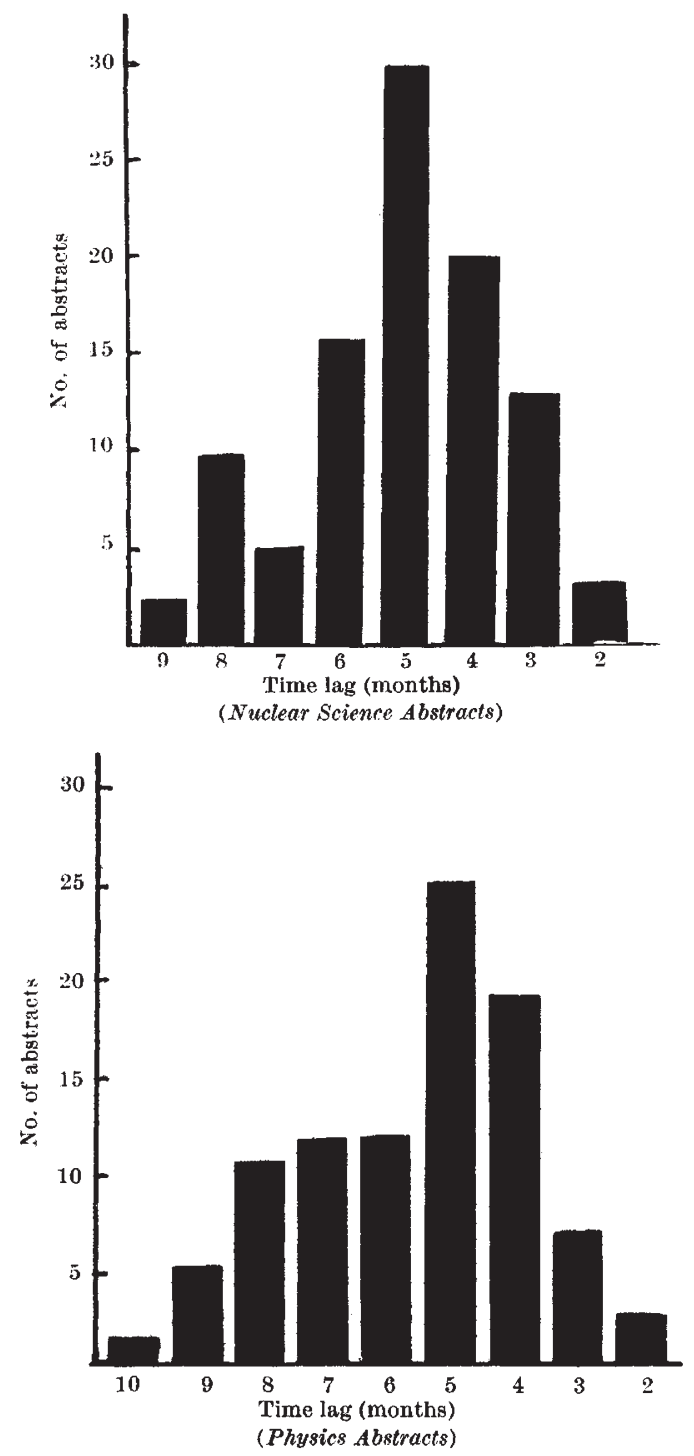

show that Nuclear Science Abstracts is slightly the quicker of the two-the median date of publication for abstracts listed in the issue of October 15 was June 4, 1967. For Physics Abstracts, published nominally on October 1 , the median date of original publication was May 18, 1967. Physicists thus had to wait nearly five months in order for abstracts to appear. In some cases, of course-and particularly in Nuclear Science $A b$ stracts - they had to wait even longer; a cursory reading of the journal brought to light a British patent"Improved Process for the Production of Graphite"-. granted as long ago as January 11, 1961, and with a priority date in France of February 29, 1956. Unfortunately, it is not only patents which take a long time to seep through; the same issue of Nuclear Science Abstracts contains a Russian paper published in English translation in January 1961, and an article from New Scientist ("Medical and Surgical Uses for the Laser", by Leon Goldman) which appeared in January 1964. Really out of date papers are much less common in Physics Abstracts, possibly because it does not include patents.

The IEE is conscious of the delay, and is hoping to accelerate the process and reduce the backlog. The recent move of the publications department to Stevenage has caused transitory difficulties, but should ultimately help to speed the process. But, despite this, there will still be an "unavoidable delay" of at least two months. Computer techniques are unlikely. to help, at least in the short term.

\section{Foot and Mouth Vaccine}

A NEw factory has been built at Grossburgwedel, outside Hanover, for the production of foot and mouth disease vaccine. The factory, which was planned, built and ready for operation within one year, is the seventh link in a chain of production units established by the Wellcome Foundation Ltd to meet demands from those countries where control measures are based on vaccination. It was opened on November 17 by Dr Fred Wrigley, deputy chairman of the foundation.

Vaccine will be produced at Grossburgwedel by a suspended cell culture technique developed by Wellcome which permits bulk production. Vaccine against those types of foot and mouth disease virus known to occur in Germany will be produced, but facilities are also available for switching production to other virus types at short notice.

The new unit, which cost about $£ 0.5$ million, covers an area of some $40,000 \mathrm{sq}$. ft. and comprises three sections. Vaccine is produced in the main laboratory building and filled and packed under a rigid control system. Vaccine is tested under the control of a government veterinary officer in the testing station, which is the second section; the third section is a quarantine stable which provides accommodation for cattle and pigs. The research team at Grossburgwedel will be led by Dr Rolf Bandau.

Foot and mouth disease vaccine is also produced in Wellcome factories in Spain, Kenya, Uruguay, Argentina and Brazil. In Britain and Eire, unlike other European countries, vaccination against foot and mouth disease is not used. It will be interesting to see whether the British Government will be compelled to change this policy by the current epidemic, still spreading. 